\title{
Leprosy in the Nose and Mouth.
}

\author{
N. Pavloff.
}

$I^{\mathrm{N}}$ $\mathrm{N}$ regard to the question of initial foci and the danger of spreading infection by "spraying" from the earliest times, the changes in the mucous membranes in leprosy has been a subject of discussion. A whole series of measures intended to guard against the infection of healthy persons have been instituted in various leper homes. A decree was once passed which compelled the lepers when conversing with a healthy person to cover their mouths with the hem of their garments or with their hands, and to stand against the wind. This treatment, after Sticker had proved the danger of infection by coughing or sneezing during a conversation, was shown to have been based on good grounds.

In our days no leprologist will deny the possibility of infection by the large quantities of bacilli expelled by coughing or sneezing, at the same time they will not side with those who are panic stricken at signs of leprosy in the mouth, nose or throat.

From a study of the literature on the subject, it will be seen that a considerable amount of attention has been given to the mucous membranes of the nose and the mouth, and but very little to the throat.

Falcao showed that the inflammation of the nose and bleeding from the nose are common initial signs of leprosy. Leloir, Jeanselme and Lorens remarked on the frequency of rhinitis found in the early stages of leprosy, and stated that infection of the nose not uncommonly precedes the appearance of manifestations on the skin. Morrow, Petersen, Sticker, and others believed that initial infection of leprosy is most frequent in the nose.* As a matter of fact, the nose of lepers very of ten shows pathological changes. This was known from ancient times, and Pliny, in describing leprosy, said: "elephantiasis a facie saepius incipientem in nare prima veluti lenticula. ..."

The presence of bacilli in the mucous membrane of the nose in the advanced, or in the initial stages of leprosy, and with manifestations in the skin, is known to every leprologist. On this question we have sufficiently convincing evidence in the book of Sir Leonard Rogers, where statistics collected from many authors are given.

- Muir and others hold that the nose is seldom, if ever, the primary lesion in leprosy.-EDiTor. 
In this paper I propose to give a morphological picture of affections met with among 200 persons and results of treatment, after painting and rinsing.

Evidently all lepers suffering from ulcers of the mucous membrane of the nose, throat and mouth are dangerous to other persons. From a prophylactic point of view it is necessary to exclude or to lessen the danger as soon as possible, and on this basis local treatment is a matter of considerable importance.

The usual clinical picture of the infection of the mucous membrane of the nose in the initial stages is the appearance of hyperæmia, erosion, infiltration (tubercles, nodules), which is often localized on the front part of the nasal septum, and owing to the swelling of the mucous membrane and the formation of crusts of ten brings in its train irregularity of breathing. Tubercles on the nasal septum have the appearance of grayish or grayish-yellow millet grains.

Besides the nasal septum the leprosy process infects the vomer and the mucous membrane of the cavities which are frequently acutely hypertrophied. Tubercles and nodules located in the cavities, reach a great size.

As a result, the septum which has already been changed by inflammation is destroyed.

When the alar cartilages are affected, the patients suffer from difficulty in breathing, owing to softening of the nodules. The scarring which follows brings about the complete closure of the nasal passage. Deformity of the nose, e.g., depression, the transverse arching at the lower extremity of the nasal bone, "lornette de theatre," crooked or snub nose, and finally parrot's beak nose-all these are very of ten seen in leprosy. I have frequently observed in leper patients crooking of the septum, especially in mixed leprosy. The material investigated gives the following results :-

\begin{tabular}{|c|c|c|c|c|}
\hline Changes. & $\begin{array}{l}\text { L. tub. } \\
51 \text { cases. }\end{array}$ & $\begin{array}{l}\text { L. Mixed. } \\
96 \text { cases. }\end{array}$ & $\begin{array}{l}\text { L.mac.-an. } \\
10 \text { cases. }\end{array}$ & $\begin{array}{l}\text { L. neural. } \\
13 \text { cases. }\end{array}$ \\
\hline 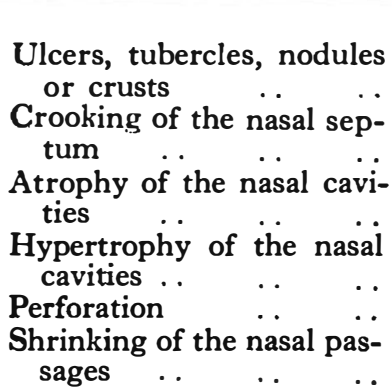 & $\begin{array}{c}\text { Per cent. } \\
\begin{array}{c}22 \\
6 \\
- \\
31 \\
41 \\
43\end{array}\end{array}$ & $\begin{array}{l}\text { Per cent. } \\
\begin{array}{l}18 \\
15 \cdot 5 \\
5 \\
27 \\
42 \cdot 5 \\
35\end{array}\end{array}$ & $\begin{array}{l}4 \text { cases } \\
1 \text { case } \\
- \\
2 \text { cases } \\
1 \text { case } \\
1 \text { case }\end{array}$ & $\begin{array}{c}\text { Per cent. } \\
15 \\
18 \\
-\end{array}$ \\
\hline
\end{tabular}


From the above table it will be seen that perforation of the nose and the complete destruction and hypertrophy of the nasal cavities are an important pathological process in leprosy.

For perforation in the initial stage, and for ulcers on the vomer or the lateral side of the nasal passage, I obtained encouraging results by daily rinsing with the following solution :-

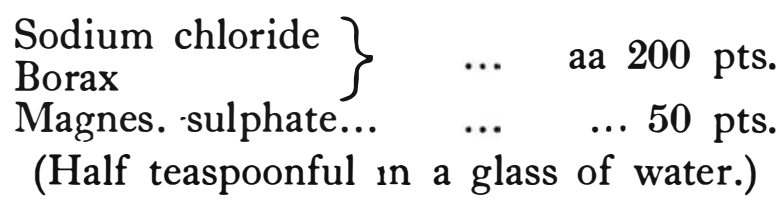

And painting with :-

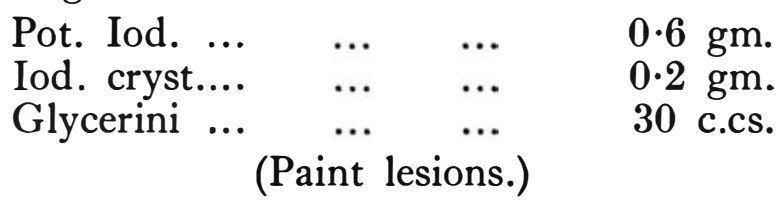

Better results are obtained in limited affections by painting with a solution of 5 per cent. chromic acid or with a solution of 50 per cent. lactic acid.

I began to use a 5 per cent. solution of chromic acid from 1926 , and believe that this drug very of ten prevents great destruction of the septum. Rinsing of the nose with the above-mentioned solution was used as a hygienic measure.

Out of 77 cases of mixed leprosy, bacilli were found in 58.7 per cent. ; 27 cases of nodular leprosy, 58 per cent. ; nerve leprosy, 36 per cent. ; and maculo anæsthetic leprosy, 40 per cent. Apparently healthy people were examined, twenty persons, who were born of leper parents, were kept under observation. They had lived with infected persons from 3 months to 21 years of age. Among them we did not find one case in which there were leper bacilli in the mucous membrane of the nose, while in one case leper bacilli were discovered in the lymphatic gland puncture - that is to say, in a patient who had been already infected by leprosy, but did not have leper bacilli in the mucous membrane of the nose.

If there are cases (Kitazato) when in a healthy person, leper bacilli have been found in the nose, then we may quote the words of Prof. V. V. Ivanoff during a speech at the Moscow Dermatological Society in 1925: " The discovery of leper bacilli in the mucous membrane of the nose among the personnel attending leper patients, without other signs, is not sufficient to justify a diagnosis of leprosy, as in the mucous membrane of the nose there may be bacilli which are either bacilli, similar in appearance to leper bacilli, or leper bacilli which have entered the nasal region from outside by breathing, but are not virulent." 
This fact to some extent denies the theory that the leprosy infection begins in the mucous membrane of the nose, and if we should take the nose as the first place of infection, then this should be done only in exceptional cases.

Leprosy infection in the mucous membrane of the mouth has a greater significance in a prophylactic sense.

Among our patients we met with tubercular or ulcerous infection in mixed leprosy ( 96 cases), 42.5 per cent. ; nodular leprosy (51 cases), 31 per cent. ; maculo-anæsthetic, out of 10 cases, only one per cent. The favourite places are the soft palate, the uvula; and the pillars of the fauces. I saw four cases out of 170 patients with tubercles on the tonsils, but I have never found ulceration.

In the initial stages the pathological process appears in the form of hyperæmia of the soft palate on which focally situated, whitish-grey tubercles of rounded form of the size of a small pea develop. Later the tubercles sink in the centre, and then they take on rounded infiltrated edges. There is a slight tendency to peripheral growth, the tubercles finally soften, ulcers are formed, and their surfaces merge and form with each other an ulcerous surface with festooned edges. Often, after the curing of the ulcers, there remain superficial cicatrices with brownish edges. Cicatrices which are localized at the base of the uvula often give sharp deformity of the arches, and the uvula inclines upwards. With considerable infection the process sometimes brings about the complete destruction of the uvula, and the cicatrices change the palatal arches to a cicatrix diaphragm which completely separates the nasa-pharynx.

Infiltrations of the hard palate are of a larger size, of a greyish-red colour, without any central depression, and chiefly break out on the surface. I have personally observed extensive erosions on the hard palate in only six cases out of 170 ; while on the soft palate ulcers, localized on the raphe, they were met with more frequently, and were distinguished by their large size. Usually these ulcers have sharply marked edges, an uneven base, and are covered by a dirty, greyish slough.

With the infection of the mucous membrane of the mouth the gums swell, and salivation increases, but I have so far never observed any elements on the gums and cheeks. It is otherwise with the mucous membrane of the lips. At the limit of the mucous membrane in the skin, and especially in the corners of the mouth, nodules may be seen, or more of ten there is an erosion of the mucous membrane with slight bleeding, and this results in incrustations being formed. Sometimes the erosions spread over the large surface of the 
lips, and this is accompanied by sharp pain. Nodules also appear on the tongue, flat infiltrations, spreading transversely or longitudinally, which are for the most part on the middle line of the tongue. On the tip of the tongue and on the sides, separate tubercles are localized. We did not observe any ulcerous depressions, but glossitis sclerotica, lingua geographica, and the increase of the follicular apparatus, especially the fungiform papillæ, were met with rather often.

All these changes greatly interfere with the food assimilating functions, and in this way local treatment has a real importance.

When the infection of the mouth is considerable, disinfecting and astringent drugs and the elementary hygiene of the mouth, give little help. After many trials of different solutions and ointments, I finally decided on a 5 per cent. solution of chromic acid; this gives very good results. Large ulcers quickly become granulated, at first flaccid, and then epithelization and scarring follows. Painting also helps when we have infiltrations. Under treatment the infiltration becomes flat, regresses, and does not ulcer. With one painting daily and rinsing, after eating, with a 2 per cent. solution of boric acid or with a 2 per cent. solution of tannic acid, the ulcers on the soft palate and uvula are usually cured in the course of two to four months.

When we have infection of the mucous membrane of the mouth, these results suggest that a 5 per cent. solution of chromic acid is a suitable and useful drug. The following illustrates this treatment. A patient was cured by preparations of chaulmoogra oil, and no ulcers appeared in the mouth. Suddenly the mucous membrane of the palate was observed to be infected, and later on large ulcers formed rather quickly. Notwithstanding the continuance of the general therapy, the ulcers were not cured. As soon as the painting with a 5 per cent. solution of chromic acid was begun, however, the ulcers quickly regressed and were cured.

We consider that chromic acid is one of the best drugs that has been tried for the cure of the leprosy process on the mucous membrane of the tongue, uvula, soft and hard palate.

As regards the infection of the arches and the tonsils, here we observed a slowing of the process of cure, but, nevertheless, chromic acid gives better results in comparison with lactic acid (painting or inhalation) and other preparations. 